\title{
Endometrial Flushing Versus Endometrial Brush Cytology in High-Risk Women for Endometrial Carcinoma
}

\author{
Emad Abd Elrahman Eltamamy ${ }^{1}$, Ahmad Taha Abd Elfattah ${ }^{1}$, Abdullah Mohammad Mokbel $^{1 *}$
}

*Corresponding Author: Abdullah Mohammad Mokbel doctorabdullah@icloud.com

Received for publication December 28, 2019; Accepted January 17, 2020; Published online January 22, 2020

\section{Copyright 2020 The Authors} published by Al-Azhar

University, Faculty of Medicine, Cairo, Egypt. All rights reserved. This an openaccess article distributed under the legal terms, where it is permissible to download and share the work provided it is properly cited. The work cannot be changed in any way or used commercially.

\section{doi:10.21608/AIMJ.2020.68889}

${ }^{I}$ Department of Obstetrics and Gynecology, Faculty of Medicine, Al-Azhar University, Cairo, Egypt.

\begin{abstract}
Background: Postmenopausal bleeding (PMB), defined as blood loss occurring at least 12 months after menopause, is a common complaint in general gynecological practice. The prevalence of PMB is approximately $10 \%$ immediately after menopause.

Aim of work: This study aims to compare two diagnostic methods, Flush and Brush cytology.

Patients and Methods: The study population comprises eighty (80) women with postmenopausal bleeding. It was conducted over 12 months from April 2018 to April 2019 on postmenopausal women who were approached, managed and followed up in the Gynecology Clinic of Minia General Hospital to compare between two diagnostic methods Flush and Brush cytology using the standard D\&C as a comparative test.

Results: The statistical results showed that the subjective pain varied significantly between the two methods: Brush and Flush. However, that difference was too little to be of clinical value. On the other hand, the objective pain showed no statistically significant difference between the two methods. Regarding tissue yield, the D\&C method provided significantly more adequate samples $(88.8 \%)$ compared with both the Flush $(30 \%)$ and Brush $(53.8 \%)$ methods (p-values, <0.05). Also, the difference between the Brush and Flush methods was statistically significant (p-value $<0.05$ ).

Conclusion: Flush and Brush are simple methods, associated with comparable pain scores. However, they have modest tissue yield which limits their clinical applicability in the screening of endometrial abnormalities in patients with postmenopausal bleeding.

Keywords: Postmenopausal bleeding; Endometrial Flushing; Brush Cytology; Carcinoma
\end{abstract}

Disclosure: The authors have no financial interest to declare in relation to the content of this article. The Article Processing Charge was paid for by the authors.

Authorship: All authors have a substantial contribution to the article

\section{INTRODUCTION}

The main objective in the diagnostic workup of postmenopausal women presenting with abnormal uterine bleeding is to detect or rule out endometrial cancer. Approximately $90 \%$ of women with endometrial carcinoma report vaginal bleeding as their only complaint, so this symptom should always be carefully investigated. However, just $10-15 \%$ of women with postmenopausal bleeding have endometrial carcinoma. ${ }^{1}$

A strategy with endometrial biopsy after endometrial thickness measurement by transvaginal ultrasound is the most cost-effective diagnostic strategy for patients with postmenopausal bleeding. ${ }^{2}$

Hysteroscopic examination with an endometrial biopsy is currently the most informative investigation for patients with abnormal uterine bleeding. ${ }^{3}$
Outpatient endometrial biopsy is the least invasive technique to obtain material for histological assessment. Pipelle endometrial biopsy is the most accurate endometrial sampling device to detect endometrial carcinoma and endometrial hyperplasia in patients with PMB. ${ }^{4}$

Directly biopsied endometrial cytology specimens can be difficult to evaluate because of blood, overlapping cells, and hormone-associated morphologic changes occurring during the menstrual cycle or resulting from hormonal therapy. ${ }^{5}$ On the other hand, recent studies have shown that using liquid-based preparation (LBP) techniques result in an improvement in the diagnostic accuracy of endometrial cytology. ${ }^{6}$

The improvement of the diagnostic capacity of the LBP method suggests that this procedure can be 
routinely used in endometrial diagnosis. The main advantages of this procedure are the reduction in confounding factors such as blood and mucus, the distribution of cells on a thin layer and the possibility to obtain more slides from the same sample. ${ }^{7}$ Brush sampler permits direct intrauterine collection of endometrial cells. ${ }^{8}$ It is an outpatient clinic procedure that could be performed without anesthesia, and it is a safe noninvasive procedure that is easy to use and well-tolerated by patients. ${ }^{9}$ Gerbaldo et al. ${ }^{10}$ proposed that on uterine flushing, endometrial cells should exfoliate from the entire endometrial lining because of the stretch of the cavity and because of the turbulence created by the flushing liquid. In their study, they concluded that collection and analysis of the flushing fluid are feasible and, when positive, have a remarkable value in the diagnosis of endometrial cancer and its precursors.

\section{PATIENTS AND METHODS}

This is a Diagnostic Test Accuracy study (DTA) which was conducted over 12 months from April 2018, to April 2019 on postmenopausal women who were approached, managed and followed up in the Gynecology Clinic of Minia General Hospital to compare between two diagnostic methods Flush and Brush cytology.

\section{Study Population:}

The study population comprised eighty (80) women with postmenopausal bleeding, fulfilling the inclusion criteria, planned for endometrial biopsy in the Gynecology Clinic of Minia General Hospital, during the study period. The whole group had been undergone the three procedures subsequently flushing, brush without anesthesia and Dilatation and Curettage under anesthesia in the operation theater. As the two methods compared to the standard D\&C and to each other. The gold standard hysteroscope for the endometrial biopsy is not used here as the facility doesn't have a hysteroscope so we did the standard D\&C due to availability and accuracy.

\section{Sample Size Justification:}

The primary outcome measure is the accuracy of either diagnostic test for the identification of patients with atypical hyperplasia or neoplasia.

A previous study reported that the sensitivity and specificity of endometrial brush cytology for the identification of atypical hyperplasia or neoplasia in patients with postmenopausal bleeding were $92 \%$ and $95 \%$, respectively. ${ }^{11}$ In that series, the prevalence of atypical hyperplasia or neoplasia among patients with postmenopausal bleeding was $12.2 \%$. However, there is no similar information at present regarding the accuracy of flush cytology.

So, it was estimated that a sample of 80 patients with postmenopausal bleeding will yield 10 (approximately 12\%) patients with atypical hyperplasia or neoplasia (positive group) and 70 (approximately 88\%) patients without atypical hyperplasia or neoplasia (negative group). This sample size would achieve a power of $81 \%$ (type II error, 0.19) to detect a difference of $42 \%$ between a null sensitivity $\left(\mathrm{Se}_{0}\right)$ of $50 \%$ for brush cytology and an alternative sensitivity $\left(\mathrm{Se}_{1}\right)$ of $92 \%$.

As regards the specificity of brush cytology, the same sample size would have a higher power of $100 \%$ to detect a difference of $45 \%$ between a null specificity $\left(S p_{0}\right)$ of $50 \%$ and an alternative specificity $\left(S p_{1}\right)$ of 95\%.

As regards the accuracy of flush cytology, the same sample size of 80 patients would achieve a power of $81 \%$ (type II error, 0.19) to detect a difference of $42 \%$ between a null sensitivity $\left(\mathrm{Se}_{0}\right)$ of $50 \%$ and an alternative sensitivity $\left(\mathrm{Se}_{1}\right)$ of $92 \%$, and a power of $100 \%$ to detect a difference of $40 \%$ between a null specificity $\left(\mathrm{Sp}_{0}\right)$ of $50 \%$ and an alternative specificity $\left(S p_{1}\right)$ of $90 \%$.

These calculations used a two-sided binomial test with a confidence level of 95\% (type I error, 0.05) and assumed that the prevalence of atypical hyperplasia or neoplasia in women with postmenopausal bleeding is approximately $12 \%$.

Ethical Approval: The study was approved by the ethics committee of the Faculty of Medicine, AlAzhar University and written informed consent was obtained from all patients.

\section{Methods}

\section{Initial Approach:}

Patients fulfilling the inclusion criteria were given an information leaflet in Arabic, which explains the procedure and its aim. Those willing to participate in the study were asked to sign an informed consent form. These patients had medical history taken and were subjected to pelvic examination for uterine size, mobility, and direction of the uterine axis.

\section{Ultrasound Scan:}

Ultrasound sonography was performed by an expert sonographer, using a transvaginal probe, $7.5 \mathrm{MHz}$ using EDAN DUOS 60 at Gynecology Clinic of Minia General Hospital.

\section{Endometrial sampling:}

A- Flushing method:

The patient was in the lithotomy position, uterine flushing was performed according to a protocol described by Mikolajczyk et al. ${ }^{12}$

Procedure: It involves placing a sterile speculum in the vagina, visualizing the cervical os and positioning a catheter into the uterine lumen which is connected to a $20 \mathrm{ml}$ syringe filled with $3.5 \mathrm{ml}$ of sterile isotonic solution of sodium chloride. The fluid was slowly infused into the uterine cavity and then gently aspirated in a repetitive fashion creating turbulent flow (to achieve a homogenous distribution of soluble factors). Next, the fluid was drawn into the syringe, which was transported to the laboratory, centrifuged and frozen in $-20^{\circ} \mathrm{C}$ for further examination. In this study, the Pipelle biopsy catheter was used without curettage of the endometrium for flushing the endometrium, not for biopsy.

B- Brush biopsy: (Cytobrush, Frank Health Ltd., Mainland, China)

Cytological sampling was performed using the cytobrush which was inserted to the level of the uterine fundus through the cervical canal and was rotated 360 degrees, then the tip of the brush was immersed in a $5 \mathrm{ml}$ tube, containing normal saline where it was vigorously stirred to facilitate the cell releasing. The tube was labeled with the patient study number. Figures $(1,2)$ 


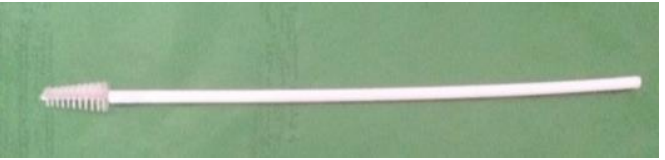

Fig.1: Brush

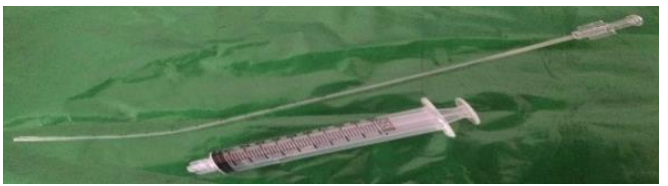

Fig.2: Pipelle

\section{C-Dilatation, and Curettage:}

The patient was in a lithotomy position under sedation with PROPOFOL in the operative theater of Minya General Hospital.

Procedure: It involves placing a sterile speculum in the vagina, visualizing the cervical os, a Volsellum was attached to the anterior lip of the cervix then dilatation of the cervix using Hegar dilators until introducing the Euro-Med Sims Endometrial Curette into the endometrial cavity, then curettage was done to obtain an endometrial sample from all the uterine walls. The biopsy specimens were placed in $10 \%$ formaldehyde and sent for histopathology. Histopathology of the endometrial sample obtained by Dilatation and Curettage was used as a reference standard.

\section{Histopathological Examination:}

The samples from both flush and brush cytology were centrifuged at $3000 \mathrm{rpm}$ (revolution per minute) up to 10 minutes and transferred into a vial containing 95\% ethyl alcohol. The Dilatation and Curettage samples were fixed in $10 \%$ formaldehyde, and then, embedded in paraffin to prepare the histology blocks. The Paraffin blocks were then cut into 1-4 $\mu \mathrm{m}$ sections using the microtome, then kept at $70^{\circ} \mathrm{C}$ for half an hour (oven air) and then stained by Hematoxylin and Eosin (H\&E) staining. The flush and brush cytology samples from all the study populations were sent with coded numbers, for independent cytological assessment to avoid bias in reporting results.

\section{Outcome measures:}

Primary outcome: The accuracy of flush and brush cytology for identification of atypical endometrial hyperplasia and neoplasia using Dilatation and Curettage histopathological diagnosis as the standard test.

\section{Secondary outcome:}

Pain perception, which was scored:

- Subjective perception of pain by asking the patient to grade the pain which perceives at the end of each procedure with scaling from 0 to 10 , where 0 means no pain, 1-3 means mild pain, 4-6 means moderate pain, and 7-10 means severe pain.

- Semi-objective perception of pain by the Visual Analogue Scale (VAS); is a graphic rating format in the form of a horizontal line for the two extremes on either end of the line.

- Observation of visual expression after each procedure was done by both a nurse attending the procedure and the study investigator. The average score was taken.

- Inadequacy of sample for examination.
- Perforation or excessive post-procedure bleeding. Statistical analysis:

Data were analyzed using IBM $\odot$ SPSS $\odot$ Statistics version 23 (IBM $\odot$ Corp., Armonk, NY, USA) and MedCalc@ version 15.8 (MedCalc@ Software bvba, Ostend, Belgium). Numerical variables were presented as mean \pm SD and range, and categorical variables as number and percentage. Paired numerical data were compared using repeatedmeasures analysis of variance. The Cochran $\mathrm{Q}$ test was used to compare paired categorical data. The inter-method agreement was tested using the weighted kappa coefficient. The accuracy of cytology methods was tested against the results of the D\&C biopsy as the standard test. P-values $<0.05$ were considered statistically significant.

\section{RESULTS}

The baseline characteristics of the study population are summarized in (Table 1).

\begin{tabular}{|c|c|}
\hline Variable & $\begin{array}{c}\text { Mean } \pm \text { SD (range) / N } \\
(\%)\end{array}$ \\
\hline Age (years) & $\begin{array}{c}61.4 \pm 6.9(48.0- \\
78.0)\end{array}$ \\
\hline $\begin{array}{l}\text { Associated } \\
\text { medical } \\
\text { disorders }\end{array}$ & ------ \\
\hline Nil & $22(27.5 \%)$ \\
\hline $\begin{array}{l}\text { Hypertensio } \\
n\end{array}$ & $16(20.0 \%)$ \\
\hline$D M$ & $29(36.3 \%)$ \\
\hline $\begin{array}{l}\text { Hypertensio } \\
n \& D M\end{array}$ & $13(16.3 \%)$ \\
\hline $\begin{array}{l}\text { Time since } \\
\text { menopause } \\
\text { (years) }\end{array}$ & $10.1 \pm 6.3(2.0-22.0)$ \\
\hline $\begin{array}{l}\text { Duration of } \\
\text { PMB } \\
\text { (weeks) }\end{array}$ & $2.4 \pm 1.1(1.0-8.0)$ \\
\hline
\end{tabular}

The mean age was $61.4 \pm 6.9$ years with a range from 48.0 to 78.0 years. Sixteen $(20 \%)$ patients had associated hypertension, 29 (36.3\%) had DM, and 13 (16.3\%) had combined hypertension and DM. The mean time since menopause was $10.1 \pm 6.3$ years (range, $2.0-22.0$ years) with a mean duration of PMB of $2.4 \pm 1.1$ years (range, 1.0 -8.0 years).

In Figure (3): A dot plot showing the frequency distribution of endometrial thickness (in $\mathrm{mm}$ ) among the study population.

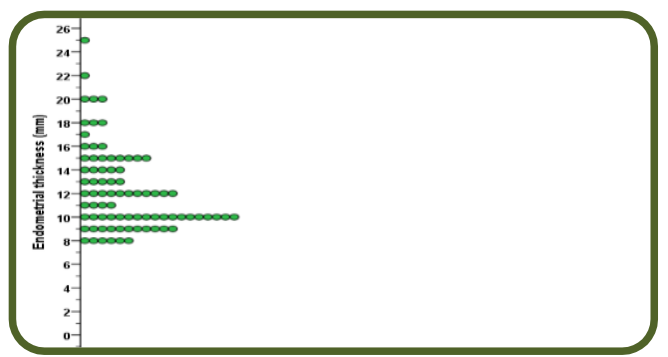

Fig.3: dot plot showing the frequency distribution of endometrial thickness in $\mathrm{mm}$ 
Table 2 shows the proportion of adequate samples obtained with the flush, brush, or D\&C method. The D\&C method provided significantly more adequate samples $(88.8 \%)$ compared with both the flush $(30 \%)$ and brush $(53.8 \%)$ methods (p-values, <0.05). The difference between the brush and flush methods was also statistically significant (p-value $<0.05$ ).

\begin{tabular}{||c|c|c|c|c|c|c||}
\hline Variable & $\begin{array}{c}\text { Flush } \\
\text { method }\end{array}$ & $\begin{array}{c}\text { Brush } \\
\text { method }\end{array}$ & $\begin{array}{c}\text { D\&C } \\
\text { method }\end{array}$ & Cochran's Q & df & $\begin{array}{c}\text { p- } \\
\text { value }\end{array}$ \\
\hline $\begin{array}{c}\text { Adequate } \\
\text { sample }\end{array}$ & $\begin{array}{c}24 \\
(30 \%)\end{array}$ & $\begin{array}{c}43 \\
(53.8 \%) \\
\dagger\end{array}$ & $\begin{array}{c}71 \\
(88.8 \%) \\
\dagger+\end{array}$ & 69.875 & 2 & $<0.001$ \\
\hline
\end{tabular}

Data are number (\%)

df, degree of freedom.

Cochran Q test.

p-value $<0.05$ versus Flush method.

p-value $<0.05$ versus Brush method.

Table 2: The proportion of adequate samples obtained with the flush, brush, or D\&C method

Table 3 shows the subjective pain score associated with the flush and brush.

\begin{tabular}{||c|c|c|c|c||}
\hline Variable & $\begin{array}{c}\text { Flush } \\
\text { method }\end{array}$ & $\begin{array}{c}\text { Brush } \\
\text { method }\end{array}$ & $\begin{array}{c}\text { F (df 1.919, } \\
\mathbf{1 5 1 . 6})\end{array}$ & p-value \\
\hline $\begin{array}{l}\text { Subjective } \\
\text { pain score }\end{array}$ & $2.26 \pm 1.06$ & $2.11 \pm 1.04 \dagger$ & 3.800 & $\mathbf{0 . 0 2 6}$ \\
\hline
\end{tabular}

Data are mean $\pm \mathrm{SD}$.

F, F statistic

df, degrees of freedom

Repeated measures analysis of variance.

Table 3: subjective pain score associated with the flush and brush

Table 4 shows the objective pain score associated with the flush and brush method. There was no statistically significant difference between the two methods ( $\mathrm{p}$-value, <0.494).

\begin{tabular}{||c|c|c|c|l||}
\hline Variable & $\begin{array}{c}\text { Flush } \\
\text { method }\end{array}$ & $\begin{array}{c}\text { Brush } \\
\text { method }\end{array}$ & $\begin{array}{c}\text { F (df 1.815, } \\
\mathbf{1 4 3 . 4})\end{array}$ & p-value \\
\hline $\begin{array}{c}\text { Objective } \\
\text { pain score }\end{array}$ & $1.9 \pm 1.0$ & $2.0 \pm 1.0$ & 0.68 & $\mathbf{0 . 4 9 4}$ \\
\hline
\end{tabular}

Data are mean \pm SD.

F, F statistic

df, degrees of freedom.

Repeated measures analysis of variance.

Table 4: objective pain score associated with the flush or brush

Table 5 shows, there was a strong correlation between the subjective and objective pain scores associated with the flush ( $\mathrm{r}=0.71$; $\mathrm{p}$-value, <0.0001). However, the differences among the correlation coefficients were not statistically significant. The correlation between subjective and objective pain scores associated with each of the two methods.

\begin{tabular}{||l|l|c||}
\hline \multicolumn{3}{|c||}{$\begin{array}{c}\text { Correlation between subjective and objective pain } \\
\text { scores }\end{array}$} \\
\hline Method & Pearson $\mathbf{r}$ & p-value (H0: $\mathbf{r}=\mathbf{0})$ \\
\hline Flush & 0.71 & $<0.0001$ \\
\hline Brush & 0.80 & $<0.0001$ \\
\hline
\end{tabular}

Table 5: Correlation between subjective and objective pain scores associated with each of the two methods
Table 6 shows the accuracy of flush cytology for the diagnosis of malignant or atypical cells as tested against the results of adequate samples by D\&C biopsy as the standard method. The flush cytology method had a sensitivity of $52.9 \%(95 \% \mathrm{CI}, 31.0 \%$ to $73.7 \%$ ), specificity of $100 \%$ (95\% CI, 91.9 to $100 \%$ ), positive predictive value (PPV) of $100 \%(95 \% \mathrm{CI}$, $100 \%$ to $100 \%$ ), and negative predictive value (NPV) of $87.1 \%$ (95\% CI, $78.8 \%$ to $95.4 \%$ ) with an overall correct classification rate (accuracy) of $88.7 \%$ (95\% CI, $81.4 \%$ to $96.1 \%$ ).

\begin{tabular}{|c|c|c|c|}
\hline \multicolumn{4}{|c|}{ D\&C biopsy } \\
\hline Flush cytology & \begin{tabular}{|c|} 
Atypical or \\
malignant \\
cells
\end{tabular} & $\begin{array}{l}\text { Non-atypical or } \\
\text { malignant cells }\end{array}$ & $\begin{array}{c}\text { Column } \\
\text { total }\end{array}$ \\
\hline \begin{tabular}{|c|} 
Atypical or \\
malignant cells
\end{tabular} & 9 & 0 & 9 \\
\hline $\begin{array}{l}\text { No atypical or } \\
\text { malignant cells }\end{array}$ & 8 & 54 & 62 \\
\hline Row total & 17 & 54 & 71 \\
\hline Statistic & Value & $95 \%$ LCL & $\begin{array}{l}95 \% \\
\text { UCL }\end{array}$ \\
\hline $\begin{array}{c}\text { Correct } \\
\text { classification }\end{array}$ & $88.7 \%$ & $81.4 \%$ & $96.1 \%$ \\
\hline \begin{tabular}{|c|} 
Misclassificatio \\
n \\
\end{tabular} & $11.3 \%$ & $3.9 \%$ & $18.6 \%$ \\
\hline Sensitivity & $52.9 \%$ & $31.0 \%$ & $73.7 \%$ \\
\hline Specificity & $100.0 \%$ & $91.9 \%$ & $100.0 \%$ \\
\hline $\begin{array}{c}\text { False positive } \\
\text { rate }\end{array}$ & $0.0 \%$ & $0.0 \%$ & $0.0 \%$ \\
\hline \begin{tabular}{|c} 
False negative \\
rate
\end{tabular} & $47.1 \%$ & $25.7 \%$ & $68.4 \%$ \\
\hline Prevalence & $23.9 \%$ & $14.0 \%$ & $33.9 \%$ \\
\hline \begin{tabular}{|c|} 
Positive \\
predictive value \\
(PPV)
\end{tabular} & $100.0 \%$ & $100.0 \%$ & $100.0 \%$ \\
\hline \begin{tabular}{|c|} 
Negative \\
predictive value \\
(NPV) \\
\end{tabular} & $87.1 \%$ & $78.8 \%$ & $95.4 \%$ \\
\hline \begin{tabular}{|c|} 
Positive \\
likelihood ratio \\
$(\mathrm{LR}+)$
\end{tabular} & - & - & - \\
\hline \begin{tabular}{|c|} 
Negative \\
likelihood ratio \\
(LR-)
\end{tabular} & 0.5 & 0.3 & 0.8 \\
\hline
\end{tabular}

95\% LCL, 95\% lower confidence limit; 95\% UCL, 95\% upper confidence limit.

Table 6: the accuracy of flush cytology for the diagnosis of malignant or atypical cells as tested against the results of adequate samples by D\&C biopsy as the standard method

Table 7 shows the accuracy of brush cytology for the diagnosis of malignant or atypical cells as tested against the results of adequate samples by D\&C biopsy as the standard method. The brush cytology method had a sensitivity of $70.6 \%$ (95\% CI, $46.5 \%$ to $86.8 \%$ ), specificity of $100 \%$ (95\% CI, 91.9 to $100 \%$ ), positive predictive value (PPV) of $100 \%$ (95\% CI, $100 \%$ to $100 \%$ ), and negative predictive value (NPV) of $91.5 \%$ (95\% CI, $84.4 \%$ to $98.6 \%$ ) with an overall correct classification rate (accuracy) of 93\% (95\% CI, $87 \%$ to $98.9 \%$ ). 


\begin{tabular}{|c|c|c|c|}
\hline \multicolumn{4}{|c|}{$\overline{\text { D\&C biopsy }}$} \\
\hline Brush cytology & $\begin{array}{c}\text { Atypical } \\
\text { or } \\
\text { malignant } \\
\text { cells }\end{array}$ & $\begin{array}{c}\text { Non- } \\
\text { atypical } \\
\text { or } \\
\text { malignan } \\
\text { t cells }\end{array}$ & $\begin{array}{c}\text { Column } \\
\text { total }\end{array}$ \\
\hline $\begin{array}{l}\text { Atypical or malignant } \\
\text { cells }\end{array}$ & 12 & 0 & 12 \\
\hline $\begin{array}{l}\text { No atypical or malignant } \\
\text { cells }\end{array}$ & 5 & 54 & 59 \\
\hline Row total & 17 & 54 & 71 \\
\hline Statistic & Value & $\begin{array}{l}95 \% \\
\text { LCL }\end{array}$ & $\begin{array}{l}95 \% \\
\text { UCL }\end{array}$ \\
\hline Correct classification & $93.0 \%$ & $87.0 \%$ & $98.9 \%$ \\
\hline Misclassification & $7.0 \%$ & $1.1 \%$ & $13.0 \%$ \\
\hline Sensitivity & $70.6 \%$ & $46.5 \%$ & $86.8 \%$ \\
\hline Specificity & $100.0 \%$ & $91.9 \%$ & $100.0 \%$ \\
\hline False positive rate & $0.0 \%$ & $0.0 \%$ & $0.0 \%$ \\
\hline False negative rate & $29.4 \%$ & $9.9 \%$ & $48.9 \%$ \\
\hline Prevalence & $23.9 \%$ & $14.0 \%$ & $33.9 \%$ \\
\hline $\begin{array}{l}\text { Positive predictive value } \\
\text { (PPV) }\end{array}$ & $100.0 \%$ & $100.0 \%$ & $100.0 \%$ \\
\hline $\begin{array}{c}\text { Negative predictive } \\
\text { value (NPV) }\end{array}$ & $91.5 \%$ & $84.4 \%$ & $98.6 \%$ \\
\hline $\begin{array}{l}\text { Positive likelihood ratio } \\
\text { (LR+) }\end{array}$ & - & - & - \\
\hline
\end{tabular}

95\% LCL, 95\% lower confidence limit; 95\% UCL, 95\% upper confidence limit.

Table (7): accuracy of brush cytology for diagnosis of malignant or atypical cells as tested against the results of adequate samples by D\&C biopsy as the standard method

\section{DISCUSSION}

the Diagnostic Test Accuracy study (DTA) was conducted on 80 women with postmenopausal bleeding and planned for endometrial biopsy to compare two diagnostic methods: Flush and Brush cytology, versus the standard D\&C biopsy.

Cytology is an important tool that complements histopathology. The main purpose of the present study is to validate the use of cytology of the endometrium as a routine diagnostic modality as it is a safe outpatient procedure without major complications.

The idea of flushing the endometrial cavity with normal saline and cytological examination of the flush was presented by several studies. Some studies used insemination cannula ${ }^{13}$, others use nasogastric tube no. $10^{14}$, others used the distension medium used in hysteroscopic examination, where a few milliliters are collected in a test tube by opening the operative channel of the hysteroscope and sent for cytological examination ${ }^{10}$, while in this study the pipelle biopsy catheter was used without curettage of the endometrium for flushing the endometrium, not for curettage.

The flush cytology method, in our study had a sensitivity of $52.9 \%$ (95\% CI, $31.0 \%$ to $73.7 \%$ ), specificity of $100 \%$ (95\% CI, 91.9 to $100 \%$ ), positive predictive value (PPV) of $100 \%$ (95\% CI, $100 \%$ to $100 \%$ ), and negative predictive value (NPV) of $87.1 \%$ (95\% CI, $78.8 \%$ to $95.4 \%$ ) with an overall correct classification rate (accuracy) of $88.7 \%$ (95\% CI, $81.4 \%$ to $96.1 \%$ ) for diagnosis of malignant or atypical cells

The flush cytology, in our study, was considered adequate in 24 patients (30\%). In 6 cases $(7.5 \%)$ malignant cells were detected all of these presented as endometrial cancer at the histopathological result of the D\&C biopsy. Also, 6 of the 13 patients diagnosed with endometrial cancer at $\mathrm{D} \& \mathrm{C}$ biopsy had malignant cells in the flush cytology, while 5 had inadequate flush cytology and 2 had atypical hyperplasia. So when the sample was considered adequate, the definition of the cytological features was always possible and sensitivity, specificity, PPV and NPV were $52.9 \%, 100 \%, 100 \%$, and $87.1 \%$ respectively.

Gerbaldo et al. ${ }^{10}$ used the distension medium in their study where they found that the endometrial washings were considered adequate in 227 patients (93.4\%), while they concluded that collection and analysis of the distension fluid is feasible and, when positive, has a remarkable value in the diagnosis of endometrial cancer and its precursors.

Patil et al. ${ }^{14}$ used nasogastric tube no. 10 for endometrial cytology, their study aimed to compare the efficacy of different methods of endometrial sampling. About $37 \%$ of endometrial samples by aspiration cytology were found to be inadequate in comparison to $4 \%$ of endometrial samples by both pipelle biopsy and dilatation and curettage methods. They found that endometrial aspiration cytology has a very low sensitivity of $26.09 \%$ with a specificity of $87.04 \%$ and a positive predictive value of $83.16 \%$. It had an accuracy of $59 \%$ in detecting premalignant and malignant endometrial pathologies $(\mathrm{p}=0,095)$. Compared to our study, they reported a similar specificity (87.04\%) and lower sensitivity (26.09\%). Regarding, the brush cytology method, thirty-seven (46.3\%) samples yielded no cells for examination, 31 (38.8\%) showed benign cells, $6(7.5 \%)$ showed atypical cells, and $6(7.5 \%)$ showed malignant cells. Also, the accuracy of brush cytology for diagnosis of malignant or atypical cells showed a sensitivity of $70.6 \%$ (95\% CI, $46.5 \%$ to $86.8 \%$ ), specificity of $100 \%$ (95\% CI, 91.9 to $100 \%$ ), positive predictive value (PPV) of $100 \%$ (95\% CI, $100 \%$ to $100 \%$ ), and negative predictive value (NPV) of $91.5 \%$ (95\% CI, $84.4 \%$ to $98.6 \%$ ) with an overall correct classification rate (accuracy) of $93 \%$ (95\% CI, 87\% to $98.9 \%$ ).

In the current study, the brush cytology was considered adequate in 43 patients $(53.75 \%)$. In 6 cases $(7.5 \%)$ malignant cells were detected, all of these presented with malignant cells at the D\&C biopsy. Also, six of the 13 patients diagnosed with cancer at D\&C biopsy had malignant cells at the brush cytology, while 4 patients had an inadequate sample, 2 patients had atypical hyperplasia and 1 had inflammatory cells

Yavuz et al. ${ }^{15}$ in their study comparing endometrial full curettage and endometrial cytology, found that endometrial cytologic specimens obtained by endometrial brush were nondiagnostic with a rate of $73.7 \%(\mathrm{n}: 42)$ and $53.8 \%(\mathrm{n}: 28)$ in postmenopausal women and reproductive period women respectively. The cytologic assessment was reported as sufficient in only $35.8 \%$ of cases. The sensitivity of endometrial cytologic evaluation in postmenopausal patients concerning sample sufficiency was found as $36 \%$, specificity $81.3 \%$, positive predictive value $60 \%$, and negative predictive value $61.9 \%$. They concluded that in both reproductive and postmenopausal patients; endometrial cytology does not appear like a method that can be used alone for 
the detection of premalignant or malignant lesions of the endometrium.

Milojkovic and Sijanovic ${ }^{16}$ have compared in their study endometrial brushing, D\&C and pap smear in 62 women in the late postmenopausal period. They found that with endometrial brush accurate diagnosis was set up in 14 from $25(56.0 \%)$ women with endometrial adenocarcinoma, with fractional curettage the diagnosis of endometrial adenocarcinoma was accurately correct in 21 from $25(84.0 \%)$ women. They concluded that cytological examination of material derived with the endometrial brush, alike vaginal cytology, is not a reliable method for discovering bleeding causes in the late postmenopausal period. Diagnostic exactness of procedure could be increased by histopathological examination of material from endometrial brush procedure and with ultrasound evaluation of endometrial thickness.

In light of these results of these studies, and following our results, the sensitivity and specificity of the endometrial cytologic examination, in terms of detecting sufficient specimen, is rather lower compared to the biopsy obtained by the endometrial biopsy. So, the use of this method in routine practice is not recommended.

\section{CONCLUSION}

In conclusion, flush and brush are simple methods, associated with comparable pain scores. However, they have modest tissue yield which limits their clinical applicability in the screening of endometrial abnormalities in patients with postmenopausal bleeding. This could be attributed, at least in part, due to the inherent lower diagnostic efficiency of conventional cytology compared to liquid-based cytology, which might prove a more promising method of cytological assessment with these methods.

\section{REFERENCES}

1. Souusa R, Silvestre M, Almeida E, et al. Transvaginal ultrasonography and hysteroscopy in postmenopausal bleeding: a prospective study. Acta Obstet Gynecol Scand. 2001; 80(9):856862.

2. Clark T, Barton $\mathrm{P}$, Coomarasamy $\mathrm{A}$, et al. Investigating postmenopausal bleeding for endometrial cancer: cost-effectiveness of initial diagnostic strategies. Bjog. 2006; 113:502-510.

3. Sharma J, Aruna J, Praveen K, et al. Comparison of efficacy of oral Drotaverne plus Mefenamic acid with paracervical block and with intravenous sedation for pain relief during hysteroscopy and endometrial biopsy. Indian $J$ Med Sci. 2009; 63(6): 244-52.

4. Dijkhuizen F, Mol B, Brolmann H, et al. The accuracy of endometrial sampling in the diagnosis of patients with endometrial carcinoma and hyperplasia: a meta-analysis. Cancer. 2000; 89:1765-1772.
5. Buccoliero A, Castiglione F, Gheri $\mathrm{C}$, et al. Liquid-based endometrial cytology: its possible value in postmenopausal asymptomatic women. Int J Gynecol Cancer. 2007; 17:182-187.

6. Firat P, Mocan G and Kapucuoglu N. Liquidbased endometrial cytology: endometrial sample collection by using Tao brush. Diagn. Cytopathol. 2002; 27(6):393-394.

7. Buccoliero A, Caldarella A, Noci I, et al. Thinlayer cytology in endometrial diagnosis. Pathologica. 2003; 95:179-184.

8. Critchley H, Warner P, Lee A, et al. Evaluation of abnormal uterine bleeding: comparison of three outpatient procedures within cohorts defined by age and menopausal status. Health Technol Assess. 2004; 8: 1-139.

9. Lavazzo C, Vorgias G, Mastorakos G, et al. Uterobrush method in the detection of endometrial pathology. Anti Cancer Research. 2011; 31:3469-3474.

10. Gerbaldo D, Papadia A, Cristoforoni P, et al. Cytological analysis of the distension fluid used during diagnostic office hysteroscopies in patients with suspected endometrial pathology. Eur J Gynaecol Oncol. 2005; 26(2): 215-8.

11. Remondi C, Sesti F, Bonanno E, et al. Diagnostic accuracy of liquid-based endometrial cytology in the evaluation of endometrial pathology in postmenopausal women. Cytopathology. 2013; 24:365-371.

12. Mikolajczyk M, Skrzypczak J, Szymanowski K, et al. The assessment of LIF in uterine flushing-a possible new diagnostic tool in states of impaired fertility. Reprod Biol. 2003; 3(3): 259-70.

13. Malik R, Agarwal R and Tandon P. Cytological assessment of endometrial washings obtained with an insemination cannula and its histological correlation. Journal of Cytology. 2008; 25(4): 128.

14. Patil P, Venigallaa S, Lingaiah $M$, et al. Comparative evaluation of the three different methods of endometrial sampling in the diagnosis of perimenopausal bleeding. $J$ Clin Gynecol Obstet. 2014; 3(4):133-137.

15. Yavuz E, Malatyalıoğlu E, Sakıncı M, et al. Assessment of reliability of endometrial brush cytology to determine the etiology of abnormal uterine bleeding and postmenopausal bleeding. Journal of Turkish Society of Obstetrics and Gynecology. 2012; 9:202-210.

16. Milojkovic M and Sijanovic S. Assessment of reliability endometrial brush cytology in detection etiology of late postmenopausal bleedings. Archives of Gynecology and Obstetrics. 2004; 269:259-262. 